\title{
The Simulation Models of Nitrogen Accumulation and Partitioning in Plant for Protected Cultivated Tomato
}

\author{
Yuli Chen ${ }^{1,2}$, Hongxin $\mathrm{Cao}^{1, *}$, Yan $\mathrm{Zhu}^{2, *}$, Yan $\mathrm{Liu}^{1}$, and Weixin Zhang ${ }^{1,2}$ \\ ${ }^{1}$ Institute of Agricultural Economics and Information /Engineering Research Center for Digital \\ Agriculture, Jiangsu Academy of Agricultural Sciences, \\ Nanjing 210014, Jiangsu Province, P.R. China \\ 2009101038@njau.edu.cn, caohongxin@hotmail.com, \\ liuyan0203@yahoo.com.cn, 2011801168@njau.edu.cn \\ ${ }^{2}$ College of Agronomy, Nanjing Agricultural University, \\ Nanjing 210095, Jiangsu Province, P.R. China \\ yanzhu@njau.edu.cn
}

\begin{abstract}
Objective】 In order to quantify the nitrogen accumulation and partitioning of protected cultivated tomato plant. 【Method】 The field experiments on cultivars and fertilizer were conducted in 2009 and 2010, and cultivars: B1, B2, and B3 were adopted. 【Result】 The simulation models of nitrogen accumulation and partitioning for protected cultivated tomato plant were built by analyzing the relationship between partitioning index and product of temperature and light in accordance with the tomato growth characteristics in this paper. The models were validated using independent experiment dataset, the results showed that RMSE, $\mathrm{X}_{\mathrm{de}}$, and $\mathrm{R}^{2}$ between simulated and measured values of nitrogen accumulation in above-ground plant and root were $0.546 \mathrm{~g} \cdot \mathrm{m}^{-2}, 0.447$ $\mathrm{g} \cdot \mathrm{m}^{-2}$, and $0.956 ; 0.041 \mathrm{~g} \cdot \mathrm{m}^{-2}, 0.033 \mathrm{~g} \cdot \mathrm{m}^{-2}$, and 0.942 , respectively. That of nitrogen accumulation in stem, leaf, and fruit were $0.165 \mathrm{~g} \cdot \mathrm{m}^{-2}, 0.132 \mathrm{~g} \cdot \mathrm{m}^{-2}$, and $0.839 ; 0.146 \mathrm{~g} \cdot \mathrm{m}^{-2}, 0.099 \mathrm{~g} \cdot \mathrm{m}^{-2}$, and $0.945 ; 0.246 \mathrm{~g} \cdot \mathrm{m}^{-2}, 0.166 \mathrm{~g} \cdot \mathrm{m}^{-2}$, and 0.845 , respectively. 【Conclusion】 This study indicated that the nitrogen accumulation and partitioning of different cultivars and fertilizer levels in the protected cultivated tomato plant could be well simulated by these models.
\end{abstract}

Keywords: protected cultivated tomato, nitrogen in plant, accumulation and partitioning, simulation models.

Foundation Information: Jiangsu Province Agricultural Scientific Technology Support Program of China (BE2011342); Jiangsu Province Agricultural Scientific Technology Innovation Fund of China (CX (10)221).

Yuli Chen (1986-), male, born in Zhucheng city of Shandong province, Main research direction: crops simulation models. $2009101038 @$ njau. edu. cn

* Corresponding author.

D. Li and Y. Chen (Eds.): CCTA 2012, Part II, IFIP AICT 393, pp. 44-52, 2013.

(C) IFIP International Federation for Information Processing 2013 


\section{Introduction}

Nitrogen is one of the necessary nutrient elements for crop growth and development. The accumulation of nitrogen have an important effects on the chlorophyll content, leaf area, photosynthetic rate, photorespiration, solar energy use efficiency, yield, quality, and so on[1]. Therefore, the systematical study for nitrogen accumulation and partitioning has an important practical significance for guiding the nitrogen application in high yield cultivation [2]. Nowadays, the studies about nitrogen accumulation and partitioning mainly were involved in the field crop, and as a basis research for protein predicting model. Chen et al. [4], Xu et al. [5], and Shi et al. [6] studied the nitrogen accumulation and partitioning of rice, barely, and wheat, respectively, and built their predicting models for protein content, respectively. However, little research on the model of nitrogen accumulation and partitioning in plant in horticultural crops were reported. The objective of this study was to build the models of nitrogen accumulation and partitioning in plant for protected cultivated tomato based on various cultivars, and fertilizer levels field experiments.

\section{Materials and Methods}

\subsection{Materials}

This study used 3 tomato cultivars representing wide variation in maturing characteristics, and they are: (B1) American mole 1(100 110days), (B2) Chaoshijifanqiedawang (109 119days), and (B3) American 903(106 116days).

\subsection{Methods}

The experiments were conducted in plastic shed with $80 \mathrm{~m}$ long, $9.8 \mathrm{~m}$ wide, and horse liver soil (the total nitrogen, $0.239 \mathrm{~g} / \mathrm{kg}$; total phosphorus, $1.297 \mathrm{~g} / \mathrm{kg}$; available phosphorus, $202 \mathrm{mg} / \mathrm{kg}$; and $\mathrm{pH}, 6.344$ in pre-planting in soils) at Suoshi village in Nanjing from July to October of 2009 (autumn crop) and from March to June of 2010 (spring crop). The experiments were a split plot design with three whole-plot treatments arranged in a randomized complete block design with three blocks and three sub-plot treatments. The whole-plot factors were the fertilizer levels: A1 (Low nitrogen: $1 / 2 \mathrm{~F}_{\mathrm{N}}$ ), A2 (Normal: $F_{N}$ ), and A3 (High nitrogen: $3 / 2 F_{N}$ ), and the sub-plot factors were varieties (B1, B2, and B3), with 3 replications and 27 plots $\left(2.96 \times 4.6 \mathrm{~m}^{2}\right)$. FN was the normal nitrogen level: compound fertilizer (N:P:K=16\%:16\%:17\%) $750 \mathrm{~kg} \cdot \mathrm{hm}^{-2}$. The planting density was 5.88 plants $/ \mathrm{m}^{2}$, the pruning method of continuous decapitation was adopted in the experiments of spring crop and autumn crop, and 3 $\sim 4$ and $2 \sim 3$ clusters were left in spring crop and autumn crop, respectively.

\subsubsection{Data Collection}

After planting, the representative samples were taken every $7 \mathrm{~d}$ from seedling to flowering and every $14 \mathrm{~d}$ during fruit period. Three representative plants selected in each treatment were separated into parts after purification and dried by the filter paper, dried in 30 min. at $105^{\circ} \mathrm{C}$, then, at $80^{\circ} \mathrm{C}$ until reaching a constant weight, measured 
using a $0.001 \mathrm{~g}$ electro-level. Then, the nitrogen contents of various organs were measured by using the micro-kjeldahl method. HOBO-H8 was placed in three different positions in the plastic shed to collect environment elements automatically every $10 \mathrm{~s}$, including air temperature, relative humidity and dew point, the absolute humidity, and light intensity, etc. In that average values every 15 minutes were recorded.

\subsubsection{Model Verification}

In this study, Excel.2007 and SPSS V 16.0 were used to analysis experimental data. The experiment data in 2009 were applied to model establishment and parameter determination, and the experiment data in 2010 were applied to model verification. The model precision was verified using root mean squared error (RMSE), mean absolute error $\left(\mathrm{X}_{\mathrm{de}}\right)$, the determined coefficient $\left(\mathrm{R}^{2}\right)$, and 1:1 plotting between measured values and simulated values. The calculation formula of RMSE and Xde can be expressed as follows:

$$
\begin{gathered}
R M S E=\sqrt{\frac{\sum_{i=1}^{n}\left(O B S_{i}-S I M_{i}\right)^{2}}{n}} \\
d e=\left|O B S_{i}-S I M_{i}\right| \\
X_{d e}=\frac{\sum d e}{n}
\end{gathered}
$$

where $\mathrm{OBS}_{\mathrm{i}}$ is measured values, $\mathrm{SIM}_{\mathrm{i}}$ is simulated values, de is absolute error, and $\mathrm{n}$ is sample numbers.

\section{$3 \quad$ Results and Analysis}

\subsection{Models Description}

\subsubsection{The Determination of Product of Temperature and Light (E)}

According to the multi factor effect principle [7], the effect of temperature and light could be expressed by the product of temperature and light $(\mathrm{E})$ :

$$
E=T \times P
$$

where $\mathrm{E}$ is product of temperature and light, $\mathrm{T}$ is effective accumulative temperature, and $\mathrm{P}$ is the accumulated light intensity which higher than light compensation point for tomato. $\mathrm{T}$ could be expressed as follows:

$$
\begin{aligned}
& T=\sum_{i=1}^{n}\left(T_{\text {mean }}-T_{b}\right) \\
& T_{\text {mean }}=\frac{T_{1}+T_{2}+T_{3}+\cdots+T_{24}}{24}
\end{aligned}
$$


where $\mathrm{T}_{\text {mean }}$ is day mean temperature, $\mathrm{T}_{\mathrm{b}}$ is minimum temperature for tomato growth, and the value is $15^{\circ} \mathrm{C}[8]$ in all development stages, besides the seedling stage is $10^{\circ} \mathrm{C}$ [7], and $\mathrm{T}_{1}, \mathrm{~T}_{2}, \mathrm{~T}_{3}, \cdots$, and $\mathrm{T}_{24}$ is the plastic shed temperature from 01:00 to 24:00, respectively.

Referring the definition of effective accumulative temperature, $\mathrm{P}$ could be expressed as follows:

$$
\begin{gathered}
P=\sum_{i=1}^{n}\left(P_{\text {mean }}-P_{b}\right) \\
P_{\text {mean }}=\frac{P_{1}+P_{2}+P_{3}+\cdots+P_{m}}{m}
\end{gathered}
$$

where $\mathrm{P}_{\text {mean }}$ is day mean light intensity, $\mathrm{P}_{\mathrm{b}}$ is light compensation point for tomato, and the value is $2 \mathrm{klx}$ [9], and $\mathrm{P}_{1}, \mathrm{P}_{2}, \mathrm{P}_{3}, \cdots$, and $\mathrm{Pm}$ is the plastic shed light intensity of integer point time from sunrise to sunset, $\mathrm{m}$ is the number of integer point time, and the time of sunrise and sunset were computed by the method of Jing et al. [10]. The other symbols were the same as above.

\subsubsection{The Models of Nitrogen Accumulation for Protected Cultivated Tomato Plant}

The changes in nitrogen accumulation with the dry matter accumulation in protected cultivated tomato plant were a Logistic curve in accordance with the data of 2009 (Fig.1).

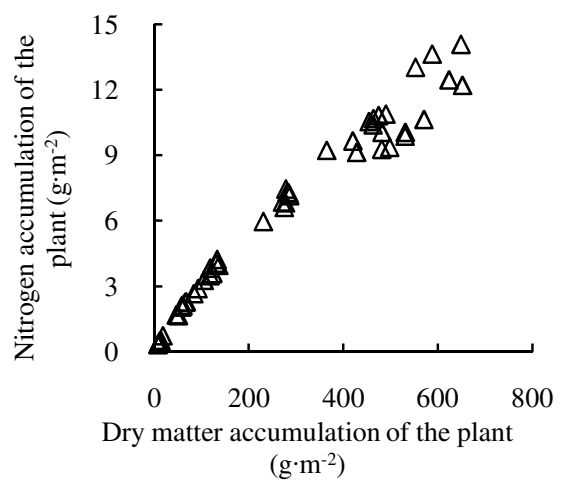

Fig. 1. The relationship between the plant Fig. 2. The relationship between nitrogen nitrogen accumulation and dry matter

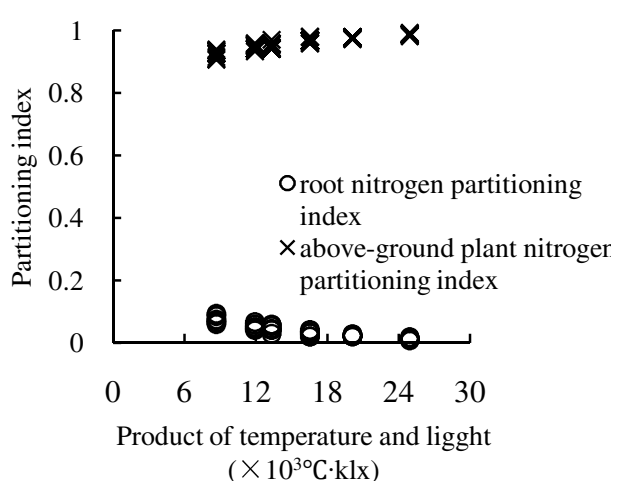
partitioning index of above-ground plant and root and $\mathrm{E}$ for protected cultivated tomato plant 
Therefore, it could be expressed as follow:

$$
N B_{E}=\frac{N B_{\max }}{\left(1+A \times e^{\left(-k \times D W_{E}\right)}\right)^{B}}
$$

where $\mathrm{NB}_{\mathrm{E}}$ is the total nitrogen accumulation in protected cultivated tomato plant at $\mathrm{E}$ in $\mathrm{g} \cdot \mathrm{m}^{-2} ; \mathrm{NB}_{\max }$ is the latent total nitrogen accumulation in protected cultivated tomato plant in $\mathrm{g} \cdot \mathrm{m}^{-2}$, and it is a model parameter; $\mathrm{DW}_{\mathrm{E}}$ is the total dry matter accumulation in protected cultivated tomato plant at $\mathrm{E}$ in $\mathrm{g} \cdot \mathrm{m}^{-2}$; and $\mathrm{A}, \mathrm{k}$, and $\mathrm{B}$ are model parameters (table 1).

Table 1. Analysis of variance for all models and its coefficient test

\begin{tabular}{lccccc}
\hline Models & Correlation & F & A & k & B \\
& coefficient & & & & \\
\hline Nitrogen contents & $0.880^{* *}$ & $96.847^{* *}$ & $0.008^{* *}$ & $0.005^{* *}$ & $322.688^{* *}$ \\
Above-ground plant nitrogen & $0.881^{* *}$ & $120.973^{* *}$ & $3.3396^{* *}$ & $0.146^{* *}$ & $0.112^{* *}$ \\
Stem nitrogen partitioning & $0.887^{* *}$ & $42.985^{* *}$ & $1.787 \times 10^{5 * *}$ & $0.894^{* *}$ & $0.106^{* *}$ \\
Stem nitrogen partitioning & $0.967^{* *}$ & $64.083^{* *}$ & $0.523^{* *}$ & $-5.046^{* *}$ & $5.198^{* *}$ \\
Leaf nitrogen partitioning index & $0.952^{* *}$ & $30.859^{* *}$ & $3.661 \times 10^{-7^{* *}}$ & $-1.389^{* *}$ & $0.066^{* *}$ \\
\hline
\end{tabular}

Note: The asterisk "*”, and "**" denoted the significant level at $\mathrm{P}<0.05$, and $\mathrm{P}<0.01$, respectively. The same below.

\subsubsection{The Models of Nitrogen Partitioning in Protected Cultivated Tomato Plant}

\subsubsection{The Simulation of Nitrogen Partitioning of Above-ground Plant and Root in Protected Cultivated Tomato Plant}

The nitrogen partitioning index to above-ground plant (root) in protected cultivated tomato plant could be expressed as follows:

$$
\begin{gathered}
N P I S=N W S H / N B \\
N P I R=1-N P I S
\end{gathered}
$$

where NPIS is the nitrogen partitioning index in above-ground plant, NPIR is the nitrogen partitioning index in root, NWSH is the nitrogen accumulation of above-ground plant in $\mathrm{g} \cdot \mathrm{m}^{-2}$, and NB is the total nitrogen accumulation in plant in $\mathrm{g} \cdot \mathrm{m}^{-2}$.

According to the relationship between the nitrogen partitioning index in above-ground plant or root and E (Fig.2), the trend could be expressed as follows: 


$$
\begin{gathered}
N P I S_{E}=\frac{N P I S_{\max }}{\left(1+A \times e^{(-k \times E)}\right)^{B}} \\
N P I R_{E}=1-N P I S_{E}
\end{gathered}
$$

where $\mathrm{NPIS}_{\mathrm{E}}$ and $\mathrm{NPIR}_{\mathrm{E}}$ is the nitrogen partitioning index in above-ground plant and root at $\mathrm{E}$, respectively. $\mathrm{NPIS}_{\max }$ is the latent nitrogen partitioning index in above-ground plant, and it is a model parameter. A, k, and B are model parameters (table 1).

\subsubsection{The Simulation of Nitrogen Partitioning for Different Organs of Above-ground Plant}

The partitioning index of nitrogen in various organs (leaf, stem, and fruit) could be expressed as follows:

$$
\begin{gathered}
N P I L=N W L / N W S H \\
N P I S T=N W S T / N W S H \\
N P I F=1-N P I L-N P I S T
\end{gathered}
$$

where NPIL, NPIST, and NPIF is the nitrogen partitioning index leaf, stem, and fruit, respectively. NWL, and NWST is the nitrogen accumulation of leaf, and stem in $\mathrm{g} \cdot \mathrm{m}^{-2}$, respectively. NWSH is the total nitrogen accumulation of above-ground plant in $\mathrm{g} \cdot \mathrm{m}^{-2}$.

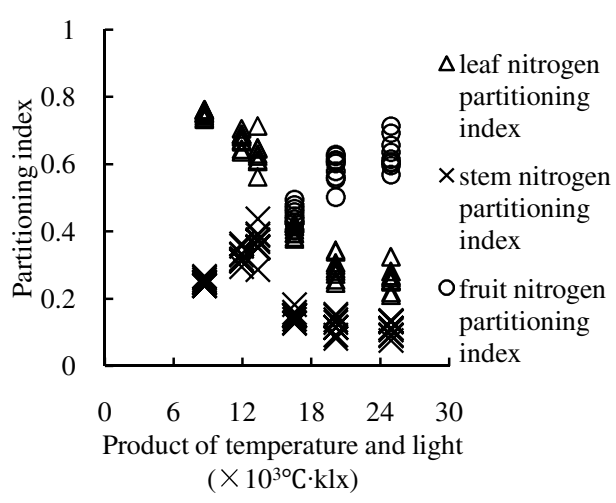

Fig. 3. The relationship between nitrogen partitioning index of stem, leaf, and fruit and $\mathrm{E}$

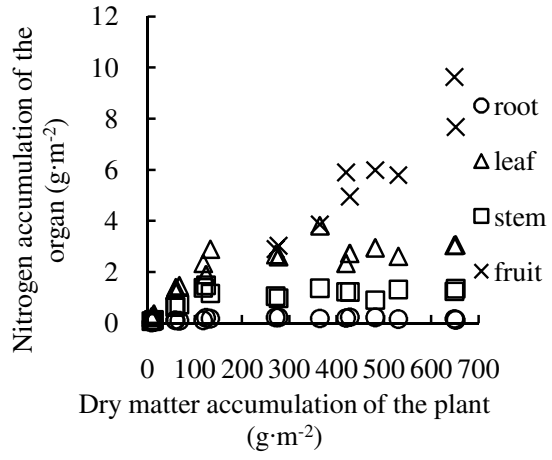

Fig. 6. The relationship between the plant nitrogen accumulation of different parts and dry matter in protected cultivated tomato plant 
The data of 2009 showed: the leaf nitrogen partitioning index decreased with the adding of $\mathrm{E}$; the stem nitrogen partitioning index increased firstly, and then decreased with the adding of $\mathrm{E}$; and the fruit nitrogen partitioning index increased with the adding of E (Fig.3).

According to the relationship between nitrogen partitioning index of leaf, stem, and fruit and E, and the trends could be expressed as follows:

$$
\begin{gathered}
N P I L_{E}=\frac{N P I L_{\max }}{\left(1+A \times e^{(-k \times E)}\right)^{B}} \\
N P I S T_{E}=\left\{\begin{array}{rr}
\frac{N^{N P I S T_{\max }}}{\left(1+A \times e^{(-k \times E)}\right)^{B}} & \left(E \leq 1.332 \times 10^{4}\right) \\
\frac{N P I S T_{\max }}{\left(1+A \times e^{(-k \times E)}\right)^{B}} & \left(1.332 \times 10^{4} \leq E \leq 2.494 \times 10^{4}\right) \\
N P I F_{E}=1-N P I L_{E}-N P I S T_{E}
\end{array}\right.
\end{gathered}
$$

where $\mathrm{NPIL}_{\mathrm{E}}$ is the leaf nitrogen partitioning index at $\mathrm{E}, \mathrm{NPIST}_{\mathrm{E}}$ is the stem nitrogen partitioning index at $\mathrm{E}, \mathrm{NPIF}_{\mathrm{E}}$ is the fruit nitrogen partitioning index at $\mathrm{E}, \mathrm{NPIL}_{\max }$ and NPIST $_{\text {max }}$ is the latent nitrogen partitioning index of leaf and stem, respectively, and it is a model parameter. A, $\mathrm{k}$, and B are model parameters (table 1).

\subsubsection{The Simulation of Nitrogen Accumulation for Different Parts in Protected Cultivated Tomato Plant}

The nitrogen accumulation of different parts of above-ground plant could be expressed as follows:

$$
\begin{aligned}
& N W S H_{E}=N B_{E} \times N P I S_{E} \\
& N W R_{E}=N B_{E} \times N P I R_{E} \\
& N W L_{E}=N W S H_{E} \times N P I L_{E} \\
& N W S T_{E}=N W S H_{E} \times N P I S T_{E} \\
& N W F_{E}=N W S H_{E} \times N P I F_{E}
\end{aligned}
$$

where $\mathrm{NB}_{\mathrm{E}}, \mathrm{NWSH}_{\mathrm{E}}, \mathrm{NWR}_{\mathrm{E}}, \mathrm{NWL}_{\mathrm{E}}, \mathrm{NWST}_{\mathrm{E}}$, and $\mathrm{NWF}_{\mathrm{E}}$ are the nitrogen accumulation of total plant, above-ground plant, root, leaf, stem, and fruit in $\mathrm{g} \cdot \mathrm{m}^{-2}$, respectively. $\mathrm{NPISH}_{\mathrm{E}}, \mathrm{NPIR}_{\mathrm{E}}, \mathrm{NPIL}_{\mathrm{E}}, \mathrm{NPIST}_{\mathrm{E}}$, and $\mathrm{NPIF}_{\mathrm{E}}$ are the nitrogen partitioning index of above-ground plant, root, leaf, stem, and fruit, respectively. 


\subsection{Model Verification}

\subsubsection{The Model Verification of Nitrogen Accumulation in Above-ground Plant and Root for Protected Cultivated Tomato}

The model of nitrogen accumulation in above-ground plant and root for protected cultivated tomato were verified by independent data in 2010 (Fig.4). The figure 4 showed: RMSE, $\mathrm{X}_{\mathrm{de}}$, and $\mathrm{R}^{2}$ of between measured and simulated values of nitrogen accumulation in above-ground plant and root for protected cultivated tomato were $0.546 \mathrm{~g} \cdot \mathrm{m}^{-2}(\mathrm{n}=36), 0.447 \mathrm{~g} \cdot \mathrm{m}^{-2}$, and $0.956 ; 0.0421 \mathrm{~g} \cdot \mathrm{m}^{-2}(\mathrm{n}=36), 0.033 \mathrm{~g} \cdot \mathrm{m}^{-2}$, and 0.942 , respectively. The correlation coefficients $(\mathrm{r})$ were $0.978\left(\mathrm{r}_{0.01,34}=0.424\right)$ and 0.971 $\left(\mathrm{r}_{0.01,34}=0.424\right)$ with 0.01 significant level, respectively.

\subsubsection{The Model Verification of Nitrogen Accumulation in Leaf, Stem, and Fruit for Protected Cultivated Tomato}

The model of nitrogen accumulation in leaf, stem, and fruit for protected cultivated tomato were verified by independent data in 2010 (Fig.5). The figure 5 showed: RMSE, $\mathrm{X}_{\mathrm{de}}$, and $\mathrm{R}^{2}$ of between measured and simulated values for protected cultivated tomato leaf, stem, and fruit nitrogen accumulation were $0.165 \mathrm{~g} \cdot \mathrm{m}^{-2}(\mathrm{n}=36), 0.132 \mathrm{~g} \cdot \mathrm{m}^{-2}$, and $0.839 ; 0.146 \mathrm{~g} \cdot \mathrm{m}^{-2}(\mathrm{n}=36), 0.099 \mathrm{~g} \cdot \mathrm{m}^{-2}$, and $0.945 ; 0.246 \mathrm{~g} \cdot \mathrm{m}^{-2}(\mathrm{n}=36), 0.166 \mathrm{~g} \cdot \mathrm{m}^{-2}$, and 0.845 , respectively. The $\mathrm{r}$ values were $0.916\left(\mathrm{r}_{0.01,34}=0.424\right), 0.972\left(\mathrm{r}_{0.01,34}=0.424\right)$ and $0.919\left(\mathrm{r}_{0.01,34}=0.424\right)$ with 0.01 significant level, respectively.

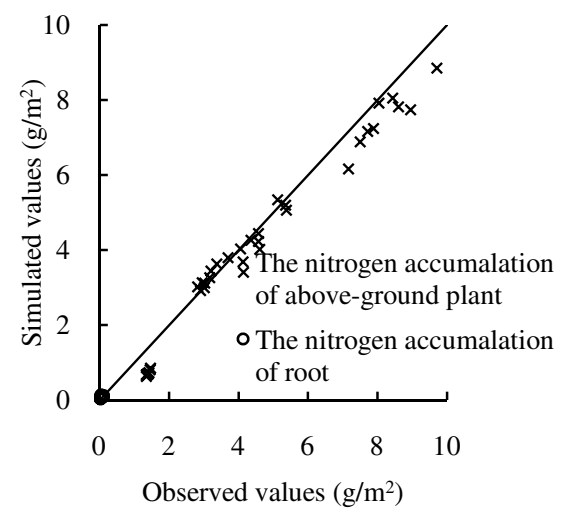

Fig. 4. Comparison of simulated with observed nitrogen accumulation values of above-ground plant and root

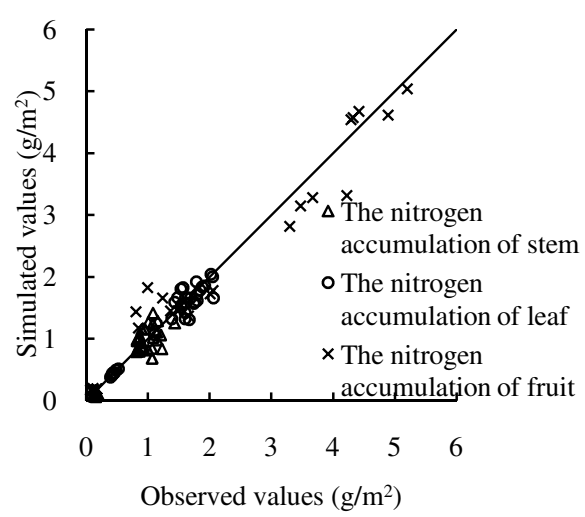

Fig. 5. Comparison of simulated with observed nitrogen accumulation values of stem, leaf and fruit 


\section{Discussion}

The amounts of nitrogen accumulation in leaf, and stem of protected cultivated tomato had a tendency to increase before topping. After topping, the amounts of nitrogen accumulation in leaf, and stem changed into little, but it increased rapidly in fruit, and roots absorbing nitrogen had little changes in the amounts of nitrogen accumulation during the total growth and development processes (Fig.6). Therefore, we could not solve the nitrogen transfer in different parts of protected cultivated tomato plant by using the thought that applied to the field crop. The nitrogen contents measured in different organs were used as the nitrogen accumulation, and the nitrogen transfer in different organs for protected cultivated tomato wasn't be studied in detail in the paper. In order to improve the applicability, accuracy, and precision of the model, the water impact factor should be considered in the model in the further studies.

\section{Conclusions}

The simulation models of nitrogen accumulation and partitioning for protected cultivated tomato were built by analyzing the relationship between nitrogen accumulation, partitioning, and biomass and $\mathrm{E}$ in accordance with the field experiment data of protected cultivated tomato in 2009 and 2010. These models were verified by using independent experiment data, the statistical analysis (RMSE, $X_{\text {de }}, R^{2}$, and $r$ ) and 1:1 diagram.

\section{References}

1. Marcelis, L.F.M.: Simulation of biomass allocation in greenhouse-A review. Acta Hort. 328, 49-65 (1993)

2. Liu, K.L., Gao, J.L., Liu, R.X., et al.: Rules of $\mathrm{N}$ assimilation, accumulation and distribution of spring wheat. J. Triticeae Crop. 23(3), 97-102 (2003) (in Chinese with English abstract)

3. Zhuang, H.Y., Cao, W.X., Jiang, S.X., et al.: Simulation on nitrogen uptake and partitioning in crops. Syst. Sci. Compr. Stud. Agric. 20(1), 5-8 (2004) (in Chinese with English abstract)

4. Chen, J., Tang, L., Liu, X.J., et al.: Modeling plant nitrogen uptake and grain protein accumulation in rice. Sci. Agric. Sin. 44(10), 1997-2004 (2011) (in Chinese with English abstract)

5. Xu, S.J., Yang, H.S., Fan, F., et al.: A model for predicting grain protein content in barley. Sci. Agric. Sin. 42(11), 3863-3870 (2009) (in Chinese with English abstract)

6. Shi, X.Y., Zhu, Y., Tang, L., et al.: Modeling dynamic grain protein composition in wheat. Sci. Agric. Sin. 42(7), 2326-2331 (2009) (in Chinese with English abstract)

7. Chen, X.J.: Research on tomato fruit development and yield formation model under facility condition. Northwest Agric. For. University, Yangling (2010) (in Chinese with English abstract)

8. Ni, J.H., Luo, W.H., Li, Y.X., et al.: Simulation of leaf area and dry matter production in greenhouse tomato. Sci. Agric. Sin. 38(8), 1629-1635 (2005) (in Chinese with English abstract)

9. Shandong Agricultural University. Vegetable cultivation to learn each theory (north this), 3rd edn. China Agric. Press, Beijing (2000) (in Chinese with English abstract)

10. Jing, C.G., Shu, D.M., Gu, D.Y.: Implementation of the times for sunrise and sunset algorithm in urban streetlight supervisory control system. Mod. Comput. 163, 84-86 (2003) (in Chinese with English abstract) 